\title{
Review
}

Neuropsychobiology

Neuropsychobiology 2013;67:61-68

DOI: $\underline{10.1159 / 000345160}$
Received: May 14, 2012

Accepted after revision: October 8, 2012

Published online: January 4, 2013

\section{Physical Exercise and Clinically Depressed Patients: A Systematic Review and Meta-Analysis}

\author{
Heitor Silveira ${ }^{a, b} \quad$ Helena Moraes ${ }^{a, b}$ Natacha Oliveira ${ }^{a, b}$ \\ Evandro Silva Freire Coutinho ${ }^{c}$ Jerson Laks ${ }^{a, d, e} \quad$ Andrea Deslandes ${ }^{a, b}$ \\ ${ }^{a}$ Center for Alzheimer's Disease and Related Disorders, Institute of Psychiatry, Universidade Federal do Rio de \\ Janeiro (UFRJ), b Neuroscience Exercise Laboratory - LaNEx (PPGCEE/UGF), 'National School of Public Health, \\ Fundação Oswaldo Cruz, d Conselho Nacional de Pesquisa (CNPq), and e Centro de Estudos e Pesquisa do \\ Envelhecimento (CEPE), Rio de Janeiro, Brazil
}

\section{Key Words}

Exercise training $\cdot$ Physical exercise $\cdot$ Strength training $\cdot$ Weight lifting $\cdot$ Unipolar depression $\cdot$ Treatment of major depression

\begin{abstract}
Objective: The aim of this meta-analysis is to evaluate the effect of aerobic training and strength training as a treatment for depression in patients diagnosed with major depressive disorder. Methods: PubMed (Medline), ISI knowledge (Institute for Scientific Information), SciELO (Scientific Electronic Library) and Scopus databases were consulted from January 1970 to September 2011. Data were collected on variables as follows: total number of patients (pre- and postintervention), age, randomized (yes or no), diagnostic criteria, assessment instruments, and the percentage of remission and treatment response. Subsequently, we collected information on time intervention, intensity, duration, frequency, method of training (aerobic training and strength training) and type of supervision. Standardized mean differences were used for pooling continuous variables as endpoint scores. Binary outcomes, such as proportion of remission (no symptoms) and at least 50\% reduction of initial scores (response), were pooled using relative risks. Random
\end{abstract}

effects models were used that take into account the variance within and between studies. Results: Ten articles were selected and subdivided by their interventions, controlled training modality and levels of intensity. As there was no statistically significant difference between the two types of intervention (strength or aerobic training), we combined data which finally showed a $0.61(95 \% \mathrm{Cl}:-0.88$ to -0.33$)$ standard deviation reduction in the intervention group compared to the control group. When the analysis was restricted only to those studies that used the Hamilton scale $(n=15)$, we observed a reduction of 3.49 points compared with the control group. Conclusion: Despite the heterogeneity of the studies, the present meta-analysis concluded that physical exercise improves the response to treatment, especially aerobic training. However, the efficacy of exercise in the treatment of depression was influenced by age and severity of symptoms.

Copyright $\odot 2013$ S. Karger AG, Basel

\section{Introduction}

Projections from the World Health Organization (WHO) have estimated that major depressive disorder (MDD) will be the second leading cause of incapacitating

\section{KARGER}

Fax +4161306 1234

E-Mail karger@karger.ch

www.karger.com
(C) 2013 S. Karger AG, Basel

0302-282X/13/0672-0061\$38.00/0

Accessible online at:

www.karger.com/nps
Heitor Silveira

Marquesa de Santos n5

Apt 702, Laranjeiras

Rio de Janeiro, RJ 22221-080 (Brazil)

E-Mail hsilveira@ufrj.br 
disease by 2020 [1]. Nowadays, the most efficient treatment for MDD includes antidepressant medication and psychotherapy; however, less than $25 \%$ of the population has access to these treatments [2]. Physical exercise has been suggested as an efficient alternative treatment to reduce symptoms of depression since it reduces cost with drugs and hospitalizations, and may also improve health and physiological responses [3-8].

There are several hypotheses regarding the physiological and psychological mechanisms by which exercise impacts on mental health, such as enhancement of the synthesis and liberation of neurotrophic factors, as well as of cognitive functioning, angiogenesis, neurogenesis and plasticity [9]. Moreover, some studies have shown that physical exercise may improve social contact, quality of life and self-esteem. Furthermore, it may also contribute to increased independence in activities of daily living in older adults $[10,11]$. Despite this wide range of possible positive effects of exercising observed in studies with humans and animals, evidence in clinical studies is still scarce [12-14].

In a recent meta-analysis, Conn [15] verified that physical exercise reduces depression symptoms in subjects without a clinical diagnosis of depression. However, systematic revision and meta-analysis studies that investigated only the clinically diagnosed depressed patients showed conflicting results $[16,17]$. Divergence about training prescription draws attention to the importance of establishing a dose response relation between physical exercise and MDD. Generally, systematic reviews and meta-analyses on the topic indicate that few studies have good methodological quality, thus making it difficult to ascertain whether exercise is really efficient for treating depression $[12,13]$.

Among the several limitations in the studies, authors included the lack of randomization, the inclusion of subjects without clinical diagnosis, and the lack of blind analysis [13]. In a recent meta-analysis, Krogh et al. [16] selected only 3 out of the 13 existing studies which had achieved good quality criteria as randomized clinical studies. Authors showed weak evidence for the benefit of exercise in depression treatment in this study.

The goal of the present meta-analysis is to evaluate the effect of aerobic and strength training as a treatment for MDD, using various aspects such as remission and response to treatment, type of exercise, weekly frequency, duration of intervention, and duration and intensity of exercise.

\section{Method}

\section{Information Sources}

PubMed (Medline), ISI knowledge (Institute for Scientific Information), SciELO (Scientific Electronic Library) and Scopus databases were consulted from January 1970 to September 2011. The PRISMA statement was used in order to build and elaborate this systematic revision and meta-analysis [18].

Search

Search was conducted according to the strategies suggested by the Medline method, using combinations among the key words: physical exercise OR aerobic exercise, nonaerobic exercise, physical activity, physical fitness, resistance, strength training, weight lifting AND major depression OR unipolar depression. Search details were: exercise [MeSH terms] OR exercise [all fields] OR (physical [all fields] AND exercise [all fields]) OR physical exercise [all fields] AND depressive disorder, major [MeSH terms] OR (depressive [all fields] AND disorder [all fields] AND major [all fields]) OR major depressive disorder [all fields] OR (major [all fields] AND depression [all fields]) OR major depression [all fields] OR depressive disorder [MeSH terms] OR (depressive [all fields] AND disorder [all fields]) OR depressive disorder [all fields] OR (major [all fields] AND depression [all fields]). In addition, article references were screened and authors were contacted for additional information. The limits accepted were longitudinal studies, clinical trials, and randomized controlled trials in humans.

\section{Study Selection}

We included articles with longitudinal design and randomized and nonrandomized clinical trials which used physical exercise (aerobic training and strength training) as a single treatment for the group, which was defined as exercise monotherapy, or combined with pharmacological treatment. In this latter case, exercise was defined as secondary or adjuvant treatment. Moreover, we included only studies that described methodological parameters of exercise prescription. Articles which were not according to the purpose of this review or which did not present the detailed methods and results so as to be evaluated and used in the metaanalysis were also excluded.

The evaluators were blinded with regard to the data referring to the names of authors, journals and/or institutes. Titles and abstracts were independently assessed by two evaluators. Whenever there was disagreement on the evaluation, another reviewer was called to give his technical opinion.

\section{Data Collection Process}

Data were collected on variables as follows: total number of patients (pre- and post-intervention), age, randomized (yes or no), diagnostic criteria, assessment instruments, the percentage of remission and treatment response. Subsequently, we collected information on time intervention, intensity, duration, frequency, method of training and type of supervision.

\section{Statistical Analysis}

We estimated the pooled effect size by standardized mean differences (SMD), as the selected studies used different scales. According to Higgins and Green [19], I ${ }^{2}$ statistics under $40 \%$ suggest that heterogeneity among studies might not be impor- 
Fig. 1. Flow chart of search and selection for the articles included in the meta-analysis.

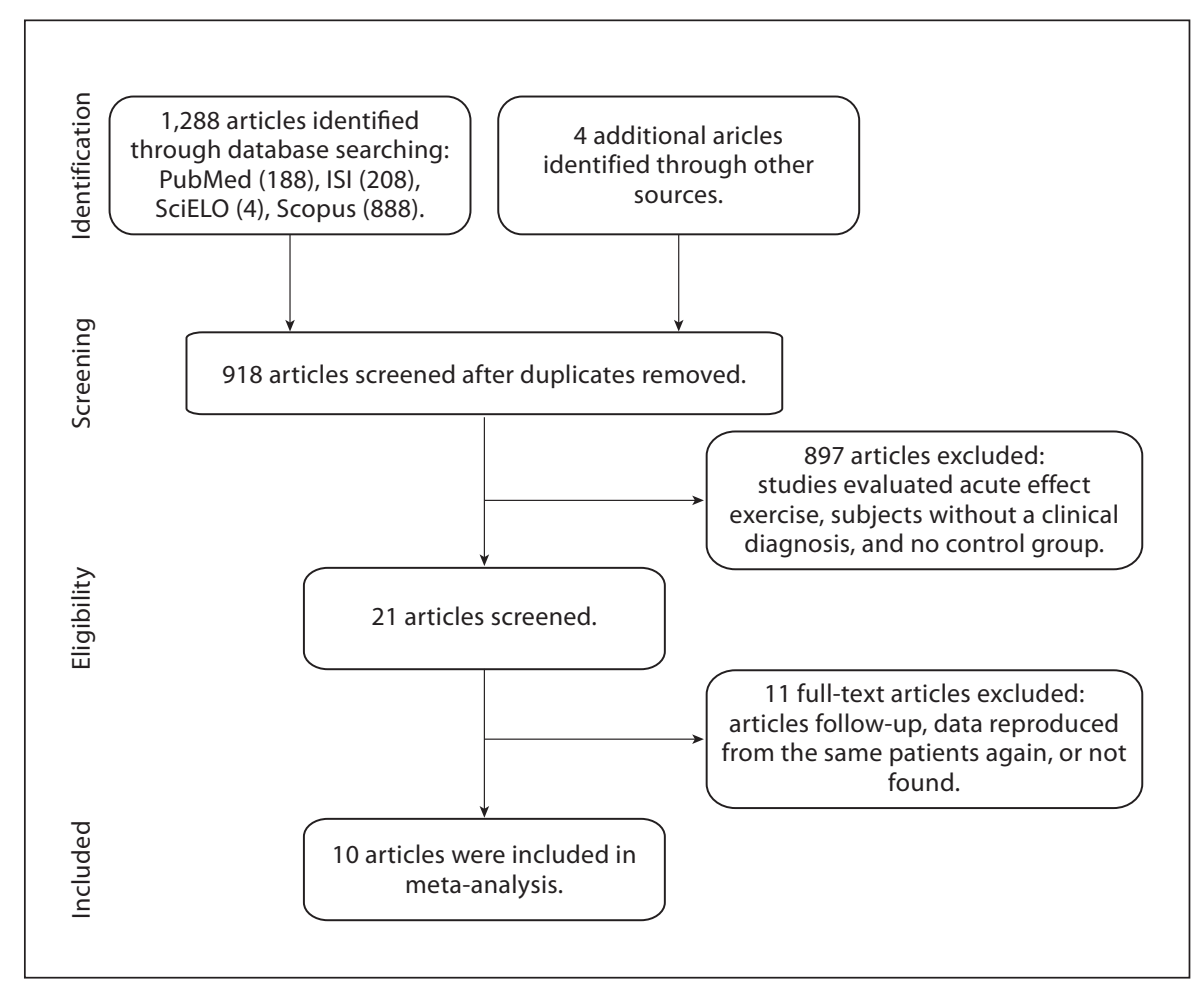

tant. On the other hand, values over 75\% indicate considerable heterogeneity, which was the case for the SMD. Moreover, the test for homogeneity was highly significant $\left(\chi^{2}=63.1\right.$; d.f. $=17$; $p<0.001)$. For this reason we used random effects models that take into account the variance within and between studies. The same analysis was repeated using only the studies that have used the Hamilton scale for depression. Binary outcomes were also used for the proportion of remission (\% reduction of MDD symptoms below the cutoff) and response (at least $50 \%$ reduction of initial scores), and the respective individual relative risks (RR) were pooled. Forest plots were used to present these findings. They were built in a way that the point estimates (SMD and RR) and 95\% CI of individual studies were graphically displayed in each line and the pooled measure was shown at the bottom. Larger horizontal lines indicate less precise (smaller) studies. The columns to the right present the numerical findings and the relative weights received by each study in the process of combining them.

Estimates with $\mathrm{p}$ values $\leq 0.05$ were considered statistically significant whilst values between 0.06 and 0.10 were suggestive (trend) of association.

Metaregression models were fitted to look into the role of the various study characteristics on the observed heterogeneity. Initially the variables were included into the model one at a time, and those with $\mathrm{p}$ values $<20 \%$ were selected for the final model. The variables with $p$ values $<10 \%$ in the final model were considered statistically significant. All analyses were performed using Stata 10.0 .

Meta-Analysis: Exercise and Clinical Depression

\section{Results}

We found 1,288 articles in the systematic search and 4 articles in the manual search. A total of 21 articles were selected, but specific cases were excluded. Two papers listed in other studies [16] located through a manual search were not found (Epstein, 1986, dissertation, and Mutrie, 1988, published in Annals of Congress), and articles that demonstrated no controlled intervention [20], or which did not show complete data $[10,21,22]$ or were just follow-up from previous research [23-27], were removed from the analysis. Ten articles were included and classified by their interventions, controlled training modality or levels of intensity. Figure 1 describes the selection process of the studies included in this meta-analysis. The characteristics of these studies are described in table 1 .

Figure 2 presents the standardized average differences in two subgroups of intervention. There was a reduction of 0.52 (95\% CI: -0.79 to -0.25$)$ and 0.96 (95\% CI: -1.97 to 0.05 ) in standard deviations for aerobic activity and strength training, respectively. We found a statistically significant difference between aerobic training and control group $(\mathrm{p}=0.001)$ and a trend for significance when strength training and control groups were compared $(\mathrm{p}=$

Neuropsychobiology 2013;67:61-68 
Table 1. Characteristics of the selected studies

\begin{tabular}{|c|c|c|c|c|c|c|c|c|c|c|c|c|}
\hline Author, year & $\begin{array}{l}\text { Number } \\
\text { of } \\
\text { patients }\end{array}$ & $\begin{array}{l}\text { Mean } \\
\text { age }\end{array}$ & Training & $\begin{array}{l}\text { Time } \\
\text { weeks }\end{array}$ & $\begin{array}{l}\text { Duration of } \\
\text { session or } \\
\text { number } \\
\text { of exercises }\end{array}$ & $\begin{array}{l}\text { Days } \\
\text { per } \\
\text { week }\end{array}$ & $\begin{array}{l}\text { Inten- } \\
\text { sity con- } \\
\text { trolled }\end{array}$ & $\begin{array}{l}\text { Super- } \\
\text { vised }\end{array}$ & $\begin{array}{l}\text { Diagnostic } \\
\text { criteria }\end{array}$ & $\begin{array}{l}\text { Level of } \\
\text { depression }\end{array}$ & $\begin{array}{l}\text { Ran- } \\
\text { domiza- } \\
\text { tion }\end{array}$ & $\begin{array}{l}\text { Type of } \\
\text { treat- } \\
\text { ment }\end{array}$ \\
\hline Klein et al. [29], 1985 & 51 & 30.1 & aerobic & 12 & 45 & - & no & yes & CIS & low/moderate & no & EM \\
\hline Veale et al. [40], 1992 & 124 & 35.5 & aerobic & 12 & - & 3 & no & yes & CIS & low/moderate & yes & CPT \\
\hline Doyne et al. [41], 1987 & 40 & 25.83 & aerobic & 8 & 20 & 3 & yes & yes & $\mathrm{RDC}$ & low & yes & EM \\
\hline Singh et al. [33], 1997 & 32 & 71.3 & strength & 10 & 50 & 3 & yes & yes & DSM-IV & low & yes & CPT \\
\hline Dunn et al. [38], 2005a & 72 & 35.9 & aerobic & 12 & - & 3 & yes & yes & DSM-IV & low/moderate & yes & EM \\
\hline Dunn et al. [38], 2005b & 72 & 35.9 & aerobic & 12 & - & 3 & yes & yes & DSM-IV & low/moderate & yes & EM \\
\hline Dunn et al. [38], 2005c & 72 & 35.9 & aerobic & 12 & - & 5 & yes & yes & DSM-IV & low/moderate & yes & EM \\
\hline Dunn et al. [38], 2005d & 72 & 35.9 & aerobic & 12 & - & 5 & yes & yes & DSM-IV & low/moderate & yes & EM \\
\hline Singh et al. [32], 2005a & 54 & 69 & strength & 8 & 60 & 3 & yes & yes & DSM-IV & low/moderate & yes & CPT \\
\hline Sing et al. [32], 2005b & 54 & 70 & strength & 8 & 60 & 3 & yes & yes & DSM-IV & low/moderate & yes & CPT \\
\hline Blumenthal et al. [30], 2007a & 202 & 53 & aerobic & 16 & 45 & 3 & yes & yes & DSM-IV & low/moderate & yes & EM \\
\hline Blumenthal et al. [30], 2007b & 202 & 53 & aerobic & 16 & 45 & 3 & yes & no & DSM-IV & low/moderate & yes & EM \\
\hline Blumenthal et al. [30], 2007c & 202 & 53 & aerobic & 16 & 45 & 3 & yes & yes & DSM-IV & low/moderate & yes & EM \\
\hline Blumenthal et al. [30], 2007d & 202 & 53 & aerobic & 16 & 45 & 3 & yes & no & DSM-IV & low/moderate & yes & EM \\
\hline Knubben et al. [37], 2007 & 38 & 49.5 & aerobic & 2 & 30 & 5 & yes & yes & DSM-IV & moderate & yes & CPT \\
\hline Krogh et al. [31], 2009a & 125 & $18-55$ & aerobic & 16 & 40 & 2 & yes & yes & ICD-10 & low/moderate & no & CPT \\
\hline Krogh et al. [31], 2009b & 125 & $18-55$ & strength & 16 & 40 & 2 & yes & yes & ICD-10 & low/moderate & no & CPT \\
\hline Silveira et al. [34], 2010 & 20 & 71.6 & aerobic & 24 & 30 & 2 & yes & yes & DSM-IV & low/moderate & no & CPT \\
\hline $\begin{array}{l}\text { Dunn, 2005a }=\text { Low inten } \\
\text { intensity } 3 \text { days } \times \text { control; } D \\
\text { Dunn, 2005d }=\text { moderate int } \\
\text { intensity } \times \text { control; Singh, } \\
\text { 2007a }=\text { supervised } \times \text { sertra } \\
\text { Blumenthal, 2007c }=\text { supervi } \\
\text { control; Krogh, } 2009 \mathrm{a}=\text { aerob }\end{array}$ & $\begin{array}{l}\text { sity } 5 \text { day } \\
5 b=\text { low } \\
\text { e; Blume } \\
\times \text { cont } \\
\times \text { contro }\end{array}$ & $\begin{array}{l}\text { ays } \times \text { c } \\
\text { w intens } \\
\text { enthal, } 2 \\
\text { trol; Blu } \\
\text { ol; Krog }\end{array}$ & $\begin{array}{l}\text { ntrol; Sing } \\
\text { ty } \times \text { cont } \\
007 \mathrm{~b}=\text { hor } \\
\text { menthal, } 2\end{array}$ & $\begin{array}{l}\text { gh, } 2005 \\
\text { trol; Blu } \\
\text { me } \times \text { s } \\
007 d=\end{array}$ & $\begin{array}{l}\text { noderate } \\
\text { control; } \\
\text { a = high } \\
\text { menthal, } \\
\text { ertraline; } \\
\text { home } \times \\
\times \text { con- }\end{array}$ & \multicolumn{7}{|c|}{$\begin{array}{l}\text { trol. } \mathrm{RDC}=\text { Research Diagnostic Criteria; } \mathrm{ICD}-10=\text { International Classifica- } \\
\text { tion of Disease 10; DSM-IV = Diagnostic and Statistical Manual of Mental } \\
\text { Disorders IV; CIS = Clinical Interview Schedule; EM = exercise monotherapy, } \\
\text { treatment is defined as a single treatment for the group; CPT = combining with } \\
\text { pharmacological treatment, is defined as secondary or adjuvant treatment for } \\
\text { the group. }\end{array}$} \\
\hline
\end{tabular}

$0.06)$. In both cases, the heterogeneity between the studies was high $\left(\mathrm{I}^{2}=69\right.$ and $88.5 \%$ for aerobic and strength, respectively). As there was no statistically significant difference between the two types of intervention, we combined the data which finally showed a 0.61 (95\% CI: -0.88 to -0.33 ) standard deviation reduction in the intervention compared with the control group $(\mathrm{p}<0.001)$.

When the analysis was restricted to those studies which used the Hamilton scale $(\mathrm{n}=15)$, we observed a reduction of 3.49 points on the intervention compared with the control group. There was no difference between the types of intervention. Also, we found a significant heterogeneity between studies $\left(\mathrm{I}^{2}=73.4 \%\right)$. When studies were restricted to those using the Hamilton scale, only aerobic interventions could be evaluated.

Remission and outcome improvement were also defined using the Hamilton scale. Remission was $14 \%$ higher in the intervention compared to the control group ( $\mathrm{RR}=1.14$; 95\% CI: 0.97-1.35), but this difference was not statistically significant ( $\mathrm{p}=0.12$; fig. 3 ). The heterogeneity for this set of studies was small $\left(\mathrm{I}^{2}=27.4 \%\right)$.

Figure 4 shows the combined RR for outcome improvement, defined as a $50 \%$ reduction in initial scores.
There was a $49 \%$ increase in the probability of response to treatment with exercise training $(\mathrm{RR}=1.49 ; 95 \% \mathrm{CI}$ : $1.10-2.03 ; \mathrm{p}=0.01$ ). No significant heterogeneity was observed in this case $\left(\mathrm{I}^{2}=22.9 \%\right)$.

According to data from the metaregression models presented in table 2 , studies which were restricted to individuals over 60 years of age showed a higher efficacy than those found in studies with populations below 60 years, but not in studies with mixed age groups. The studies including patients with moderate/mild depressive symptoms showed a lower efficacy than that observed in studies restricted to patients with mild depressive symptoms.

\section{Discussion}

This meta-analysis investigated the effect of physical exercise in reducing depressive symptoms in MDD patients. We were able to confirm that physical exercise provides moderate benefits (SMD $=0.61$ ) as a treatment for depression. An interesting result of the present study was to acknowledge that physical exercise is an efficient alter- 


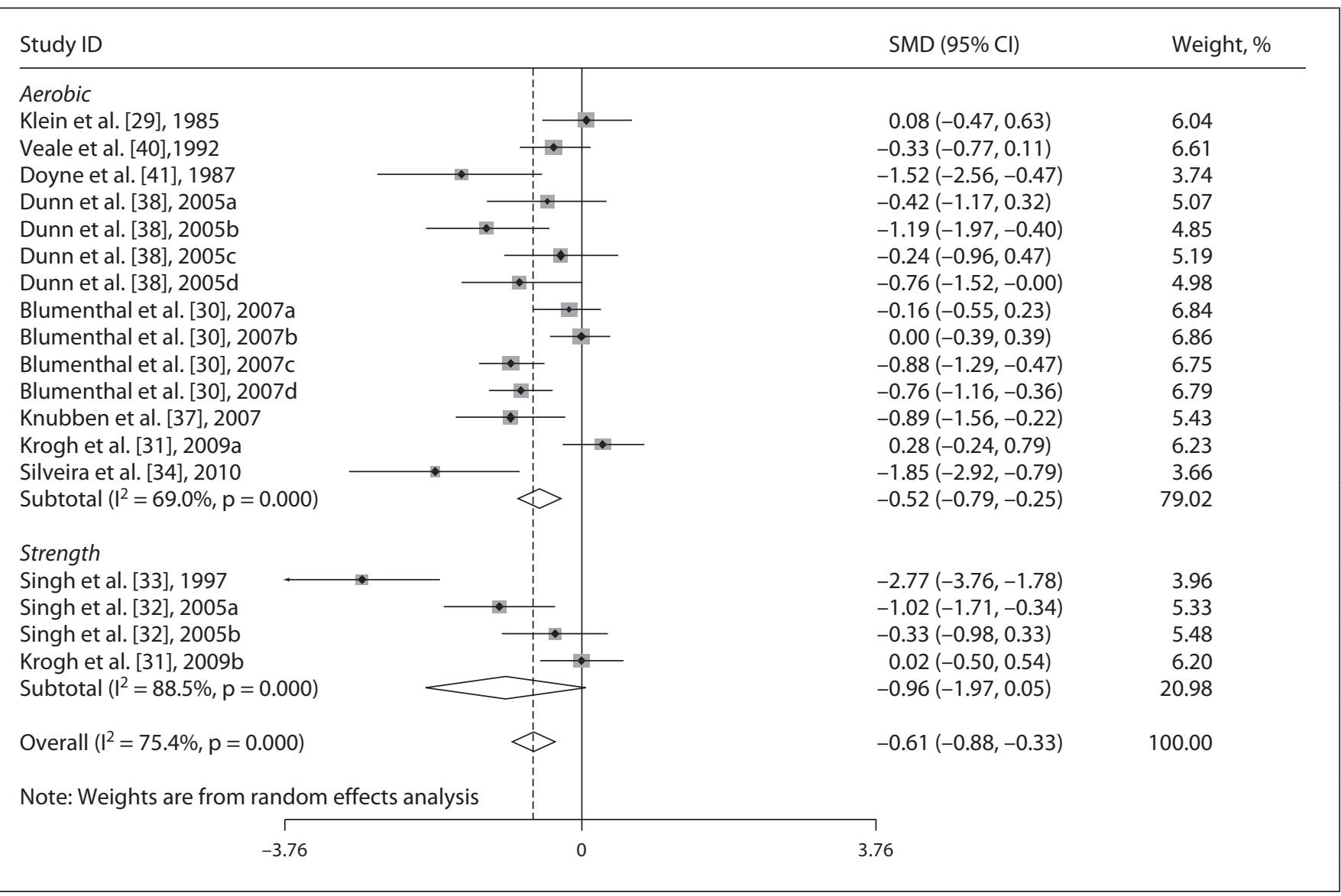

Fig. 2. Meta-analysis of studies assessing the effect of exercise in patients with clinically diagnosed depression by intervention.

native treatment for depression, promoting a $49 \%$ increase in the probability of response to treatment. Our results are in line with other meta-analysis studies, which have observed an improvement in the quality of publications in this area of research $[12,16,28]$. Seminal studies showed some methodological problems (e.g. nonrandomized controlled trials, no blinding of outcome assessment, and nonclinical populations) $[20,21]$ whilst recent clinical trials have shown stronger experimental designs [30-32].

In the present study, the efficacy of exercise in the treatment of depression was influenced by age and symptom severity. By using metaregression models, we were able to find that elderly subjects and patients with mild depressive symptoms presented a better treatment response with physical exercise than controls. Singh et al. [33] have demonstrated that strength training can reduce depressive symptoms and promote improvements in sev- eral aspects of quality of life, such as pain, vitality and social functioning. Moreover, Silveira et al. [34] have observed that depressive elderly patients showed increased brain cortical activity and significantly reduced depressive symptoms after 6 months of aerobic training. Blumenthal et al. [30, 35] have verified that aerobic training is as effective as antidepressant medication (sertraline) in reducing depressive symptoms. Therefore, it is reasonable to present the hypothesis that physical exercise may in some cases be considered an alternative to antidepressants for the treatment of MDD in older persons. This important finding might contribute to decreasing the use of medication and hospitalization and in promoting independence in activities of daily living in elderly patients, an outcome not usually observed in youths due to a 'ceiling effect'. It is important to highlight that the samples of all studies included in this meta-analysis consisted of patients with mild or moderate depression. This feature 


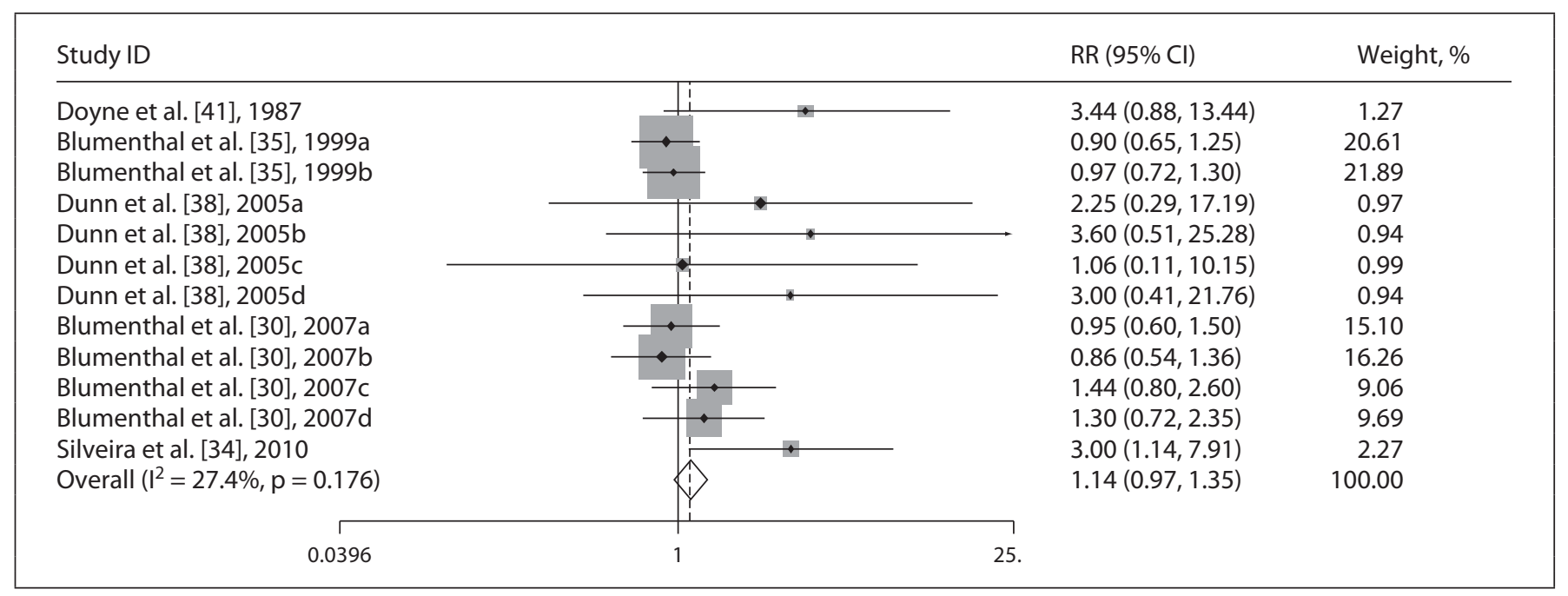

Fig. 3. Meta-analysis of studies assessing the remission of symptoms through the effect of exercise in patients with clinically diagnosed depression.

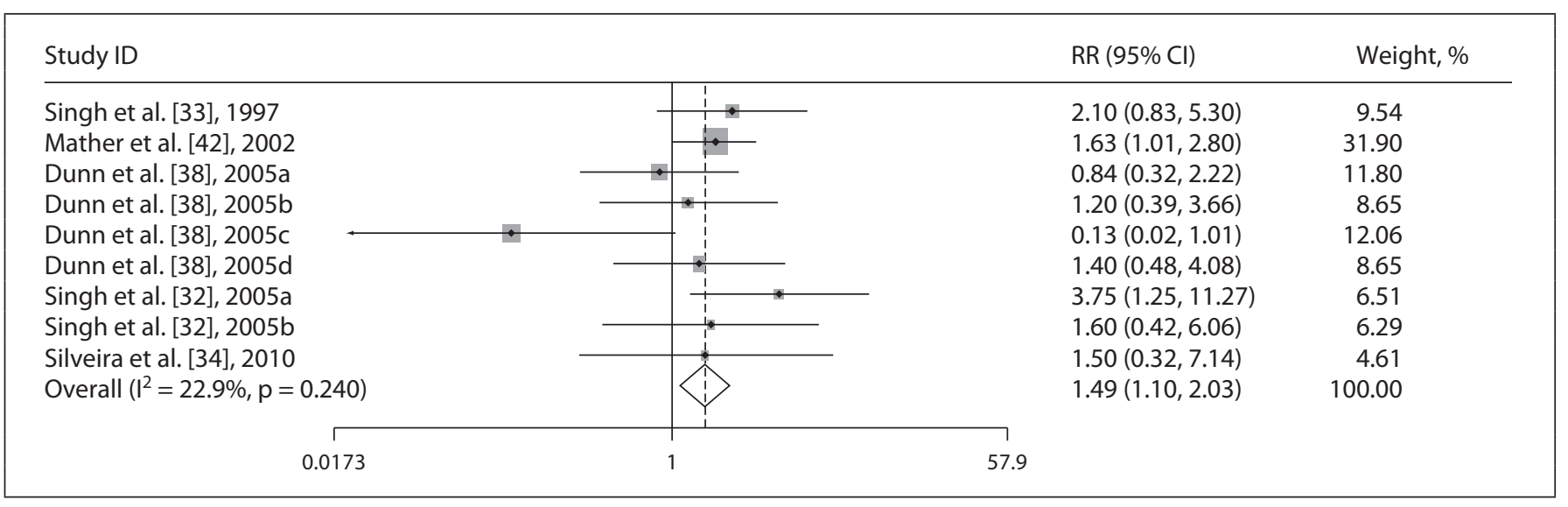

Fig. 4. Meta-analysis of studies assessing the combined RR for outcome improvement, defined as a $50 \%$ reduction in initial scores, of depression symptoms through the effect of exercise in patients with clinically diagnosed depression.

Table 2. Multivariate metaregression of the effect size of SMD according to age group and depression severity of patients

\begin{tabular}{llll}
\hline SMD & Coefficient & $\mathrm{p}$ & $95 \% \mathrm{CI}$ \\
\hline Age $>60$ years & -0.74 & 0.041 & $-1.45,-0.03$ \\
Mixed age & -0.26 & 0.317 & $-0.81,0.28$ \\
Severity & 1.53 & 0.007 & $0.49,-2.57$ \\
Constant & -1.77 & 0.002 & $-2.81,-0.74$ \\
\hline
\end{tabular}

66

Neuropsychobiology 2013;67:61-68 might also contribute to adherence due to a lower depressive symptom.

In an animal study, Russo-Neustadt et al. [36] have verified that both physical exercise and antidepressants promoted an increase in the synthesis of BDNF mRNA, a trophic factor which is a key in the establishment of neurogenesis and neuronal survival. Besides that, authors noted that exercise plus antidepressants provided an interaction response in both interventions, increasing the expression of BDNF mRNA. Considering that depression 
is associated with a decrease of BDNF synthesis whereas neurogenesis and antidepressant and physical exercise promotes an inverse response, it is conceivable to hypothesize that these neurobiological changes could contribute to explaining the effect of exercise as an additional treatment to depression. To the best of our knowledge, there are no randomized clinical trial studies which have so far investigated the effect of exercise on these parameters.

We showed that training parameters such as frequency, intervention period, intensity and duration of training, and the fact that it is supervised or not, do not exert any influence on the response to treatment. However, we should emphasize that the vast majority of studies have performed similar protocols, i.e. 30-60 min of moderateintensity activities and low frequency $\left(3\right.$ days $\cdot$ week $\left.^{-1}\right)$, whereas only 1 study evaluated the effect of physical exercise with higher frequency (5 days week $\left.^{-1}\right)$ [37]. With respect to intensity, as no study has investigated vigorous intensities (above $90 \% \mathrm{VO}_{2 \max }$ ), we are not able to make any inference on the effects of these intensities in the treatment of depression. The latest results show that the best response on mood is obtained by moderate effort intensity. Regarding exercise duration, Dunn et al. [38] have verified that there is no difference between training 3 days week $^{-1}$ and training 5 days $\cdot$ week $^{-1}$. Authors concluded that an energy expenditure of $17 \mathrm{kcal} \cdot \mathrm{kg} \cdot$ week $^{-1}$ is more efficient than spending $7 \mathrm{kcal} \cdot \mathrm{kg} \cdot \mathrm{week}^{-1}$, independent of frequency. This energy expenditure is equivalent to the recommendations from the American College of Sports Medicine which indicates at least $150 \mathrm{~min} \cdot$ week $^{-1}$ [5] as the best practice. Only $15 \mathrm{~min} \cdot \mathrm{day}^{-1}$ or $90 \mathrm{~min} \cdot$ week ${ }^{-1}$ of moderate-intensity exercise is enough to provide significant benefits to physical health, especially to subjects with cardiovascular or metabolic diseases [39]. Despite the ideal recommendation, recent studies have demonstrated that exercising twice a week, with $30 \mathrm{~min}$ duration and moderate intensity can contribute to decreasing depressive symptoms in elderly subjects with MDD [23, 34].

After a 12-month investigation, results indicated that both training conditions (aerobic and strength training) reduced depressive symptoms. The utilization of one type of exercise (aerobic or strength) showed that it is efficient in the reduction of depression symptoms of clinically depressed patients $[30,32,34]$. Future studies that investigate other types of exercise (swimming, whole body vibration training, flexibility) and combine many modalities should be done.

Overall, our results point out that adding a routine of supervised physical exercise to pharmacological treat- ment would be the most suitable routine for elderly people with MDD so as to further improve the treatment response.

Some methodological problems still persist in the available studies, such as the absence of clinical diagnosis of MDD, the absence of supervised control group and exercises without intensity, and the methodological control of training parameters and exercise prescription $\left(\mathrm{VO}_{2 \max }, \% \mathrm{RM}\right)$. Future studies should include biomarker analyses and neuroimaging studies in order to better understand the neurophysiological effects and the role of the exercise in the treatment of depression.

\section{Conclusion}

The present meta-analysis concluded that physical exercise, mainly aerobic training, improves the response to depression treatment. However, the efficacy of exercise in the treatment of depression was influenced by age and severity of symptoms.

\section{Acknowledgments}

This work was supported by Conselho Nacional de Pesquisa (CNPq) and Coordenação de Aperfeiçoamento de Pessoal de Nível Superior (CAPES), Rio de Janeiro, Brazil.

E.S.F.C. and J.L. were partially supported by the National Council for Scientific and Technological Development (CNPq), process No. 306575/2011-6 and 300411/2009-0, respectively.

We thank the following people for their assistance during data collection: Monique Carvalhaes, Ingrid Storck, Paulo Vasques, Alexandre Santos, Dannyel Barbirato, Alessandro Carvalho, Cynthia Arcoverde, Thiago Guimarães, Eduardo Portugal, Leticia Brito and Narahyana Bom de Araújo.

\section{Disclosure Statement}

The authors have no conflicts of interest that are directly relevant to the content of this review.

References

Neuropsychobiology 2013;67:61-68
1 World Health Organization: World Health Statistics: Ten Statistical Highlights in Global Public Health. Geneva, WHO, 2007, pp 9-20.

2 Halliwell E, Richardson C, McCulloch A, Ryrie I: Up and Running? Exercise Therapy and the Treatment of Mild or Moderate Depression in Primary Care. London, Mental Health Foundation, 2005. 
3 Craft LL, Perna FM: The benefits of exercise for the clinically depressed. Prim Care Companion J Clin Psychiatry 2004;6:104-111.

-4 Taylor CB, Sallis JF, Needle R: The relation of physical activity and exercise to mental health. Public Health Rep 1985;100:195-202.

$\checkmark 5$ Chodzko-Zajko WJ, Proctor DN, Fiatarone Singh MA, Minson CT, Nigg CR, Salem GJ, Skinner JS, American College of Sports Medicine: American College of Sports Medicine position stand. Exercise and physical activity for older adults. Med Sci Sports Exerc 2009;41:1510-1530.

6 Craft LL: Exercise and clinical depression: examining two psychological mechanisms. Psychol Sport Exerc 2005;6:151-171.

7 Stella F, Gobbi S, Corazza DI, Costa JLR: Depressão no idoso: Diagnóstico, tratamento e benefícios da atividade física. Motriz 2002;8: 91-98.

8 Brosse AL, Sheets ES, Lett HS, Blumenthal JA: Exercise and the treatment of clinical depression in adults: recent findings and future directions. Sports Med 2002;32:741-760.

-9 Deslandes A, Moraes H, Ferreira C, Veiga H, Silveira H, Mouta R, Pompeu FA, Coutinho ES, Laks J: Exercise and mental health: many reasons to move. Neuropsychobiology 2009; 59:191-198.

10 Singh NA, Clements KM, Singh MA: The efficacy of exercise as a long-term antidepressant in elderly subjects: a randomized, controlled trial. J Gerontol A Biol Sci Med Sci 2001;56:M497-M504.

-11 Peluso MA, Guerra de Andrade LH: Physical activity and mental health: the association between exercise and mood. Clinics (Sao Paulo) 2005;60:61-70.

$\checkmark 12$ Rethorst CD, Wipfli BM, Landers DM: The antidepressive effects of exercise: a metaanalysis of randomized trials. Sports Med 2009;39:491-511.

13 Lawlor DA, Hopker SW: The effectiveness of exercise as an intervention in the management of depression: systematic review and meta-regression analysis of randomised controlled trials. BMJ 2001;322:1-8.

14 Sjösten N, Kivelä SL: The effects of physical exercise on depressive symptoms among the aged: a systematic review. Int J Geriatr Psychiatry 2006;21:410-418.

15 Conn VS: Depressive symptom outcomes of physical activity interventions: meta-analysis findings. Ann Behav Med 2010;39:128-138.

- 16 Krogh J, Nordentoft M, Sterne JA, Lawlor DA: The effect of exercise in clinically depressed adults: systematic review and metaanalysis of randomized controlled trials. J Clin Psychiatry 2011;72:529-538.

17 Stathopoulou G, Powers MB, Berry AC, Smits JAJ, Otto MW: Exercise interventions for mental health: a quantitative and qualitative review. Clin Psychol (New York) 2006; 13:179-193.

-18 Liberati A, Altman DG, TetzlaffJ, Mulrow C, Gotzsche PC, Ioannidis JP, Clarke M, Devereaux PJ, Kleijnen J, Moher D: The prisma statement for reporting systematic reviews and meta-analyses of studies that evaluate health care interventions: explanation and elaboration. Ann Intern Med 2009;151:W65W94.

19 Higgins JP, Green S: Cochrane Handbook for Systematic Reviews of Interventions. Chichester, Wiley, 2008, vol 8, p 649.

20 Greist JH, Klein MH, Eischens RR, Faris J, Gurman AS, Morgan WP: Running as treatment for depression. Compr Psychiatry US 1979;20:41-54

21 Martinsen EW, Medhus A, Sandvik L: Effects of aerobic exercise on depression: a controlled study. Br Med J (Clin Res Ed) 1985; 291:109.

22 Martinsen EW, Hoffart A, Solberg O: Comparing aerobic with nonaerobic forms of exercise in the treatment of clinical depression: a randomized trial. Compr Psychiatry 1989; 30:324-331.

23 Deslandes AC, Moraes H, Alves H, Pompeu FA, Silveira H, Mouta R, Arcoverde C, Ribeiro P, Cagy M, Piedade RA, Laks J, Coutinho ES: Effect of aerobic training on EEG alpha asymmetry and depressive symptoms in the elderly: a 1-year follow-up study. Braz J Med Biol Res 2010;43:585-592.

24 Babyak M, Blumenthal JA, Herman S, Khatri P, Doraiswamy M, Moore K, Craighead WE, Baldewicz TT, Krishnan KR: Exercise treatment for major depression: maintenance of therapeutic benefit at 10 months. Psychosom Med 2000;62:633-638.

25 Ossip-Klein DJ, Doyne EJ, Bowman ED, Osborn KM, McDougall-Wilson IB, Neimeyer RA: Effects of running or weight lifting on self-concept in clinically depressed women. J Consult Clin Psychol 1989;57:158-161.

26 Herman S, Blumenthal JA, Babyak M, Khatri P, Craighead WE, Krishnan KR, Doraiswamy PM: Exercise therapy for depression in middle-aged and older adults: predictors of early dropout and treatment failure. Health Psychol 2002;21:553-563.

27 Hoffman BM, Babyak MA, Craighead WE, Sherwood A, Doraiswamy PM, Coons MJ, Blumenthal JA: Exercise and pharmacotherapy in patients with major depression: oneyear follow-up of the smile study. Psychosom Med 2011;73:127-133.

28 Mead GE, Morley W, Campbell P, Greig CA, McMurdo M, Lawlor DA: Exercise for depression. Cochrane Database Syst Rev 2009: CD004366.

29 Klein MH, Greist JH, Gurman AS, Neimeyer RA, Lesser DP, Bushnell NJ, Smith RE: A comparative outcome study of group psychotherapy vs. exercise treatments for depression. Int J Ment Health 1985;13:148-177.

30 Blumenthal JA, Babyak MA, Doraiswamy PM, Watkins L, Hoffman BM, Barbour KA, Herman S, Craighead WE, Brosse AL, Waugh R, Hinderliter A, Sherwood A: Exercise and pharmacotherapy in the treatment of major depressive disorder. Psychosom Med 2007;69:587-596.
31 Krogh J, Saltin B, Gluud C, Nordentoft M: The DEMO trial: a randomized, parallelgroup, observer-blinded clinical trial of strength versus aerobic versus relaxation training for patients with mild to moderate depression. J Clin Psychiatry 2009;70:790800.

-32 Singh NA, Stavrinos TM, Scarbek Y, Galambos G, Liber C, Fiatarone Singh MA: A randomized controlled trial of high versus low intensity weight training versus general practitioner care for clinical depression in older adults. J Gerontol A Biol Sci Med Sci 2005;60:768-776.

33 Singh NA, Clements KM, Fiatarone MA: A randomized controlled trial of progressive resistance training in depressed elders. J Gerontol A Biol Sci Med Sci 1997;52:M27M35.

- 34 Silveira H, Deslandes AC, de Moraes H, Mouta R, Ribeiro P, Piedade R, Laks J: Effects of exercise on electroencephalographic mean frequency in depressed elderly subjects. Neuropsychobiology 2010;61:141-147.

- 35 Blumenthal JA, Babyak MA, Moore KA, Craighead WE, Herman S, Khatri P, Waugh R, Napolitano MA, Forman LM, Appelbaum M, Doraiswamy PM, Krishnan KR: Effects of exercise training on older patients with major depression. Arch Intern Med 1999;159: 2349-2356.

36 Russo-Neustadt A, Ha T, Ramirez R, Kesslak JP: Physical activity-antidepressant treatment combination: impact on brain-derived neurotrophic factor and behavior in an animal model. Behav Brain Res 2001;120:87-95.

- 37 Knubben K, Reischies FM, Adli M, Schlattmann P, Bauer M, Dimeo F: A randomised, controlled study on the effects of a shortterm endurance training programme in $\mathrm{pa}$ tients with major depression. Br J Sports Med 2007;41:29-33.

38 Dunn AL, Trivedi MH, Kampert JB, Clark CG, Chambliss HO: Exercise treatment for depression: efficacy and dose response. Am J Prev Med 2005;28:1-8

39 Wen CP, Wai JP, Tsai MK, Yang YC, Cheng TY, Lee MC, Chan HT, Tsao CK, Tsai SP, Wu $\mathrm{X}$ : Minimum amount of physical activity for reduced mortality and extended life expectancy: a prospective cohort study. Lancet 2011;378:1244-1253.

40 Veale D, Fevre KL, Pantelis C, Souza V, Mann A, Sargenant A: Aerobic exercise in the adjunctive treatment of depression: a randomized controlled trial. J Royal Soc Med 1992;85:541-544.

41 Doyne JE, Ossip-Klein DJ, Bowman ED, Osborn KM, McDougall-Wilson IB, Neimeyer RA: Running versus weight lifting in the treatment of depression. J Consult Clin Psychol 1987;55:748-754.

42 Mather AS, Rodrigues C, Guthrie MF, McHarg AM, Reid IC, McMurdo MET: Effects of exercise on depressive symptoms in older adults with poorly responsive depressive disorder. Br J Psychiatry 2002;180:411-415. 